\title{
Autoimmune Attack of the Neuromuscular Junction in Myasthenia Gravis: Nicotinic Acetylcholine Receptors and Other Targets
}

\author{
Mariela L. Paz ${ }^{\dagger}$ and Francisco J. Barrantes*, ${ }^{*} \oplus$ \\ ${ }^{\dagger}$ Immunology Department, Faculty of Pharmacy and Biochemistry, IDEHU-CONICET, University of Buenos Aires, Junin 956, \\ C1113AAD Buenos Aires, Argentina \\ ${ }^{\ddagger}$ Laboratory of Molecular Neurobiology, Biomedical Research Institute (BIOMED), UCA-CONICET, Av. Alicia Moreau de Justo \\ 1600, C1107AFF Buenos Aires, Argentina
}

\begin{abstract}
The nicotinic acetylcholine receptor (nAChR) family, the archetype member of the pentameric ligand-gated ion channels, is ubiquitously distributed in the central and peripheral nervous systems, and its members are the targets for both genetic and acquired forms of neurological disorders. In the central nervous system, nAChRs contribute to the pathological mechanisms of neurodegenerative disorders, such as Alzheimer and Parkinson diseases. In the peripheral nerve-muscle synapse, the vertebrate neuromuscular junction, "classical" myasthenia gravis (MG) and other forms of neuromuscular transmission disorders are antibody-mediated autoimmune diseases. In MG, antibodies to the nAChR bind to the postsynaptic receptors and activate the classical complement pathway culminating in the formation of the membrane attack complex, with the subsequent destruction of the postsynaptic apparatus. Divalent nAChR-antibodies also cause internalization and loss of the nAChRs.

Autoimmune attack of the neuromuscular junction Loss of receptors by either mechanism results in the muscle weakness and

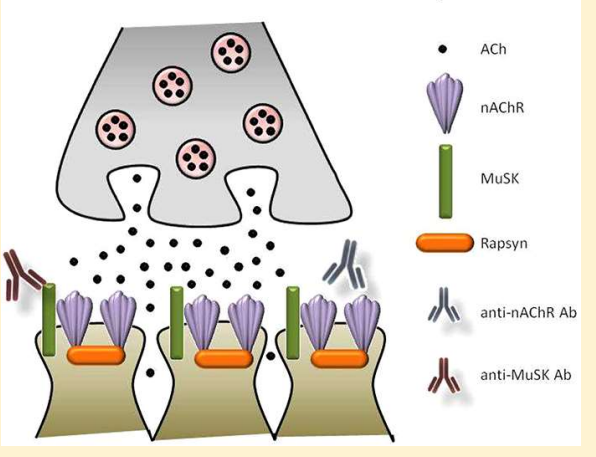
fatigability that typify the clinical manifestations of the disease. Other targets for antibodies, in a minority of patients, include muscle specific kinase (MuSK) and low-density lipoprotein related protein 4 (LRP4). This brief Review analyzes the current status of muscle-type $\mathrm{nAChR}$ in relation to the pathogenesis of autoimmune diseases affecting the peripheral cholinergic synapse.
\end{abstract}

KEYWORDS: Myasthenia gravis, neuromuscular junction, end plate, nicotinic acetylcholine receptor, autoimmune diseases, antireceptor antibody

\section{INTRODUCTION}

The superfamily of pentameric ligand-gated ion channels (pLGIC) is composed of neurotransmitter receptor proteins which, during the course of evolution, acquired and perfected the ability to transduce chemical into electrical signals and thus mediate fast communication. ${ }^{1}$ These receptors share a common architecture of five subunits pseudosymmetrically arranged around a central pore, the ionic channel. Their structural similarity extends to sharing a relatively large extracellular domain, which carries the ligand recognition site (the canonical or orthosteric agonist binding site) at the subunit interfaces. They also have in common four $\alpha$-helical transmembrane segments (M1-M4) in each subunit, making a total of 20 membrane-embedded polypeptide segments in the transmembrane domain, whose elements are connected by extra- and intracellular links. The transmembrane segments, and the five M2 helices in particular, conform the walls of the ion channel proper and the functional domain determining the gating of the channel. The transmembrane domain is also involved in allosteric modulation of channel function. Finally, the intracellular cytoplasmic domain, much smaller than the extracellular domain, carries sites for channel regulation via posttranslational modifications and is indirectly involved in channel conductance.

The pLGIC superfamily includes the nicotinic acetylcholine receptor (nAChR) families, $\gamma$-aminobutyric acid type A or $\mathrm{C}$ $\left(\mathrm{GABA}_{\mathrm{A} / \mathrm{C}}\right)$ receptors, glycine receptors (GlyR), the subtype 3 of the serotonin $\left(5-\mathrm{HT}_{3}\right)$ receptor families, and the glutamategated chloride channel $(\mathrm{GluCl})^{2}$ family. In terms of their functional properties, these receptors can be divided into two categories: cation-selective channels ( $\mathrm{nAChR}$ and $5-\mathrm{HT}_{3}$ receptors) and anion-selective channels (glycine and $\mathrm{GABA}_{\mathrm{A} / \mathrm{C}}$ receptors). They are widely distributed throughout diverse phyla in the animal kingdom ${ }^{1,2}$ and unique combinations of ionic selectivity and cellular/tissue distribution determine their specialized functions in brain and elsewhere.

Dysfunction of pLGICs results in several disorders of the central (CNS) and peripheral (PNS) nervous systems. ${ }^{2}$ In many instances, these pathologies involve the ion conduction pathway of the macromolecules in question, falling into the category of "channelopathies", a term coined more than two

Received: January 16, 2019

Accepted: March 27, 2019

Published: March 27, 2019 
decades ago. ${ }^{3}$ Several CNS neurological and neuropsychiatric disorders may be called channelopathies. For instance, nAChRs have been reported to function abnormally in schizophrenia spectrum disorders, bipolar disorders, eating disorders, stress, addictions and in particular nicotine addiction and alcohol use disorders, cognitive and memory disorders, autism spectrum disorders, psychoses, and certain forms of epilepsy. ${ }^{4,5}$ Alzheimer and Parkinson diseases, both likely of multifactorial origin, ${ }^{6}$ stand out among the disorders involving CNS nAChRs, and their commonalities, such as cognitive impairment evolving more frequently than not into terminal dementia, are tightly linked to nAChR dysfunction. In the CNS, the nAChR molecule is expressed in various combinations of subunits in different brain regions, not only in neuronal cells, but also in astroglia, microglia, oligodendroglia, and endothelial cells. ${ }^{7}$ It is thus not surprising that the pathologies associated with $\mathrm{nAChR}$ dysfunction are so pleomorphic and exhibit such a wide repertoire of signs and symptoms.

In addition to the wide distribution of the $\mathrm{nAChR}$ in the CNS and PNS, its widespread occurrence in non-neural tissues $^{7}$ has gained relevance in connection with the antiinflammatory role it plays in pathological conditions such as ischemia, rheumatoid arthritis and pancreatitis, among others. Its expression is also of medical importance in lung and breast due to the involvement of these receptors in carcinomas of these organs: ${ }^{8,9}$ e.g. an oncogenic role is attributed to the $\mathrm{nAChR},{ }^{10}$ thus making it a possible therapeutic target. ${ }^{11}$

In the PNS, myasthenia gravis $(M G)^{12}$ is the best characterized disease related to $\mathrm{nAChR}$ dysfunction. The pathogenic effectors as well as the biomarkers of MG are a group of autoantibodies mainly directed at the nAChR. ${ }^{13}$ Other proteins present at the neuromuscular junction $(\mathrm{NMJ})^{14}$ have been reported to also elicit an autoimmune response similar to that observed with the $\mathrm{nAChR}$, although rarer, and their pathogenic mechanisms are of additional interest.

Several comprehensive reviews on $\mathrm{nAChR}$ and MG have appeared during recent decades (see, e.g., refs 13 and 15-19). This short Review attempts to summarize the current state of knowledge on nAChR structure, the molecular cascades of the clustering mechanisms involved in NMJ development, and the pathogenesis of the autoimmune disease MG affecting the muscle end-plate nAChR. In addition to the discussion of the "classical" target of the autoimmune attack extensively studied during the last few decades, the nAChR macromolecule, other membrane proteins present at the NMJ have been identified as immune targets in recent years and are also analyzed in this review.

\section{THE MUSCLE-TYPE nAChR}

The $\mathrm{nAChR}$ is a pentameric macromolecule of roughly a quarter of a million Daltons made up of five subunits. So far, $17 \mathrm{nAChR}$ different subunits have been found in the animal kingdom. There are two main types: $\alpha$ and non- $\alpha$. The muscletype $\alpha 1$-subunit containing $\mathrm{nAChR}$ occurs at the NMJ of vertebrates $^{14,20}$ and the electroplax of elasmobranch and teleost electric fish like the fresh water eel Electrophorus electricus and salt water Torpedinidae, respectively. The two latter constitute faithful model systems for which most of the molecular properties of the muscle-type receptor have been characterized over the course of the last five decades. The muscle-type nAChR is made up of $2 \alpha$ and one $\beta, \delta$, and $\gamma$ each in its fetal form and $2 \alpha, \beta, \delta$, and $\varepsilon$ in the adult stage. ${ }^{21,22}$ In the muscle-type receptor, the acetylcholine (ACh) binding sites are located at the interface of the $\alpha-\delta$ and the $\alpha-\gamma(\varepsilon)$ subunits. ${ }^{23}$ Three loops contributed by each $\alpha$-subunit, termed $\mathrm{A}, \mathrm{B}$ and $\mathrm{C}$, form one wall of the canonical agonist recognition site; loops $\mathrm{D}, \mathrm{E}$ and $\mathrm{F}$, provided by the non- $\alpha$ subunits, constitute the complementary wall of the binding site. ${ }^{24}$ Figure 1 shows the overall architecture of the muscle-type nAChR.

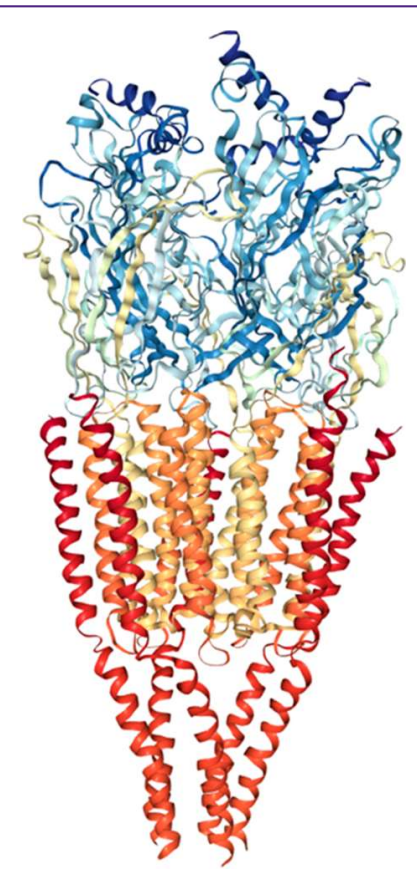

Figure 1. $\mathrm{nAChR}$ molecule. Three domains are apparent: a large extracellular domain with abundant $\beta$-strand secondary structure (upper portion, in various grades of blue and light yellow), the allhelical transmembrane region (middle portion, in yellow and red), comprising 20 helices, 4 from each subunit, and the smaller cytoplasmic region with a single helix from each subunit (bottom portion, salmon colored). The molecular model was drawn using the molecular coordinates from the density maps deposited in the Protein Data Bank in Europe of the PDB file with the accession number $4 \mathrm{BOR}^{25}$ http://www.ebi.ac.uk/pdbe/ and the software MolSoft Browser vers. 3.8 .

The muscle-type nAChR was the first neurotransmitter receptor system to be explored at the single-molecule level with the single-channel patch-clamp recording technique. ${ }^{26-28}$ The single-channel activity of the muscle-type receptor consists of bursts of individual openings originating from the same channel, separated by relatively long interburst silent periods of channel inactivity in which the nAChR is in the desensitized state. It has been possible to ascertain that the much shorter silent periods within a burst (the intraburst closed time) correspond to the transitions between unliganded, closed states and the biliganded, full open channel state of the receptor.

\section{PATHOGENESIS AND CLINICAL MANIFESTATIONS OF MG}

In MG, most of the autoantibodies (Abs) are directed at the $\mathrm{nAChR}$. This receptor has a set of antibody epitopes which are mainly located around a loop of amino acids 66-76 on the $\alpha 1$ subunit that has been called the main immunogenic region (MIR); many but not all autoantibodies of MG patients bind to this region. ${ }^{22}$ When this loop interacts with the $\mathrm{N}$-terminal amino acids $1-14$ of the $\mathrm{nAChR} \alpha 1$ subunit, the receptor 
Table 1. Clinical Subtypes of MG and Their Antibodies ${ }^{a}$

\begin{tabular}{|c|c|c|c|c|c|}
\hline MG subtype & $\begin{array}{l}\text { age at } \\
\text { onset }\end{array}$ & thymic status & $\mathrm{nAChR} \mathrm{Ab} /$ isotype (incidence) & other Abs & refs \\
\hline \multicolumn{6}{|l|}{ generalized } \\
\hline $\begin{array}{l}\text { early } \\
\text { onset }\end{array}$ & $<40$ years & hyperplasia & $+/ \operatorname{IgG} 1-3(80 \%)$ & & $\begin{array}{l}37,39,40,45-47 \\
65\end{array}$ \\
\hline $\begin{array}{l}\text { late } \\
\text { onset }\end{array}$ & $>40$ years & normal & $+/ \operatorname{IgG} 1-3(80 \%)$ & anti-titin, anti-ryanodine ( $50 \%)$ & $37,49-54,65,83$ \\
\hline ocular & variable & unknown & $+/ \operatorname{IgG} 1-3(50 \%)$ & & $33,34,37,38,65$ \\
\hline SNMG & variable & hyperplasia in some & $\begin{array}{l}\text { some present antibodies against clustered nAChR/ } \\
\text { IgG1 }(66 \%)\end{array}$ & & $106,108-110$ \\
\hline
\end{tabular}

${ }_{\mathrm{n}} \mathrm{AChR}=$ nicotinic acetylcholine receptor. $\mathrm{MG}=$ myasthenia gravis. $\mathrm{MuSK}=$ muscle-specific receptor tyrosine kinase. $\mathrm{SNMG}=$ seronegative $\mathrm{MG}$.

adopts a change in its three-dimensional configuration that enhances antibody binding to the MIR. ${ }^{29}$

MG is an organ-specific autoimmune disease that meets all Witebsky's postulates of autoimmunity: it is an autoantibodymediated pathology, the corresponding antigens have been identified, and an analogous autoimmune response can be induced by the purified protein in experimental animal models. The disease in animals can be elicited either by immunization or by passive transference of human MG Abs. ${ }^{30}$

Historically, MG was originally described as a disease affecting the NMJ and caused by anti-nAChR autoantibodies. $^{12,15,31}$ The clinical manifestations of the disease result from the alteration of the transmission of impulses between the nerve and the muscle. The muscular weakness associated with fatigability constitutes the cardinal symptom. Autoimmune MG currently has a reported worldwide prevalence of 40-180 per million, and an annual incidence of 4-12 per million individuals. The fact that these figures are considerably higher than earlier reports is mainly due to the increased longevity of many populations ${ }^{32-34}$

Acute exacerbation of the disease is manifest in the appearance of potentially life-compromising swallowing disorders and respiratory failure. ${ }^{35}$ Patients with MG have a 10 to $20 \%$ risk of developing a myasthenic crisis or exacerbations throughout their life, mainly during the first year of evolution. ${ }^{36}$

It is increasingly accepted that MG is a disease with high variability in its clinical expression and that it is currently possible to recognize different MG subtypes according to the autoantibody profile, age of onset, haplotype, distribution of muscle commitment and associated thymic pathology, when present $^{16,37}$ (Table 1).

Antibody titer appears not to be correlated with disease severity; the lack of correlation can be attributed to differences in the effector function of the different types of Abs. Nonetheless, monitoring the titer of MG Abs is likely to provide useful information on the course of the disease at the individual patient level. At the population level, MG patients exhibit a wide variety of Abs, and in $80-90 \%$ of cases it is possible to detect Abs directed toward the nAChR (nAChR$\mathrm{Ab}) .^{38}$ These circulating Abs are responsible for the blockage and reduction of the number of receptors in the postsynaptic membrane by endocytic mechanisms. ${ }^{12}$ Within the group of nAChR-Ab patients, $20 \%$ show weakness restricted to the eye muscles (ocular MG) and the other $80 \%$ have extraocular muscle weakness, with a multiplicity of skeletal muscles affected (generalized MG). ${ }^{34}$ Thymic abnormalities are frequently found in generalized MG patients, and the highest antibody titers are observed in patients with thymic follicular hyperplasia $^{39,40}$ (see Table 1). In $40-70 \%$ of patients negative for nAChR-Ab, Abs can be detected against another postsynaptic protein, MuSK (muscle-specific tyrosine kinase). ${ }^{41,42}$ These patients usually exhibit generalized MG, and are mostly young adults who do not show any thymic abnormalities. ${ }^{43,44}$

For quite some time, MG has been regarded as a disorder affecting young women and older men. A large body of studies has demonstrated that $\mathrm{nAChR}-\mathrm{Ab}$ MG patients can currently be divided into early onset (EOMG) and late-onset (LOMG) disease groups, each showing differential characteristics ${ }^{33,37}$ (see Table 1). EOMG is defined as onset of the first symptom before the age of 40-50, these patients often being female, with thymic hyperplasia. ${ }^{45-47}$ Thymectomy is recommended in most such cases, and patients respond favorably to the surgery, improving their condition. An association with human leukocyte antigen (HLA) haplotypes has been reported, where EOMG patients are likely to have the HLA-B8-DR3 haplotype. $^{48}$

The first symptoms in patients with LOMG appear after the age of 40-50. Initially, this form of the disease was thought to more frequently affect male individuals, though now it has been established that the sex ratio is nearer unity. ${ }^{49}$ LOMG have normal or atrophic thymus glands; therefore, thymectomy is not recommended for this group. These patients often present autoantibodies to striated muscle proteins, such as titin or the ryanodine receptor, ${ }^{50}$ and only a weak association with the HLA-B7-DR2 haplotype has been found. ${ }^{51,52}$ There is a steep rise in the incidence of MG in older patients, ${ }^{53}$ with a peak between 70 and 80 years of age. ${ }^{54}$ Some patients as old as 100 years have been diagnosed in recent times. ${ }^{55}$ This may be the result of both improved prognoses and more advanced diagnostic procedures such as the widespread use of autoantibody testing, which lead to the recognition that many older patients acquire the disease ${ }^{51}$ (see Table 1).

Regarding association with genotypes other than HLA, it has been shown that the APOE4 allele present in some individuals with potentially relevant disorders of cholesterol metabolism might affect the seropositive status of MG patients. ${ }^{56}$ It has also been reported that the intensity of the immune response may be affected in MG patients who are APOE2/4 carriers. ${ }^{57}$ In this regard, Sostarko and co-workers ${ }^{57}$ showed a positive correlation between a group of patients diagnosed with the severe form of MG (all of whom presented high nAChR-Ab titers), and the presence of the APOE2/4 genotype, which was in fact the most frequent genotype among MG patients. The $A P O E 3 / 3$ genotype was the most frequent among the healthy 
controls. The latter was not confirmed in a subsequent study by Suhail et al., ${ }^{56}$ but these authors did confirm the association between the presence of the APOE4 allele with nAChR-Ab positive patients.

In addition to the MG forms described above and their genetic associations, there is another group of myasthenic pathologies termed congenital myasthenia gravis or congenital myasthenic syndromes (CMS), which are characterized by a genetic defect, typically inherited from both parents, rather than an autoimmune disease with immune attack to the NMJ. ${ }^{58,59}$ These genetic disorders are also associated with impaired neuromuscular transmission and the main molecules involved, among others, are presynaptic enzymes and transporters (ChAT, ChT, MUNC13-1, MYO9, PREPL, SYT2, VAChT, and VAMP1), synaptic basal lamina proteins (COLQ and COL13A1), and also postsynaptic proteins (nAChR subunits: $\alpha, \beta, \delta$ and $\varepsilon$, AGRN, DOK7, MUSK, LRP4, and rapsyn). ${ }^{60}$ Other genes encoding for ubiquitous molecules (GFPT1, DPAGT1, ALG2, ALG14, and GMPPB) related to post-translational modifications of postsynaptic proteins (such as $\mathrm{N}$-glycosylation) have also been implicated in CMS. There are more than 30 CMS causative genes identified up to date, reviewed in detail by Rodriguez-Cruz and co-workers. ${ }^{61}$

\section{ANTI-nAChR ANTIBODIES AND THE IMMUNE ATTACK OF THE NMJ}

Pathogenic $n A C h R-A b s$ bind to functional nAChRs, reducing their number at the motor end plate and resulting in a characteristic pattern of muscle weakness. ${ }^{62,63}$ There are three main mechanisms underlying the loss of functional nAChRs, all of which are $\mathrm{Ab}$-dependent: ${ }^{64}$ (i) complement-mediated lysis of the NMJ, resulting in simplification of the postsynaptic muscle membrane; (ii) accelerated internalization and degradation of $\mathrm{nAChRs}$ caused by cross-linkage of nAChRs by specific IgG; and to a lesser extent (iii) blockade of the $\mathrm{nAChR}$ by Abs which bind specifically to acetylcholine binding sites.

The most widely studied and physiopathologically relevant of these harmful mechanisms is complement-mediated lysis of the NMJ. The fact that nAChR-Abs belong mainly to the IgG1 and IgG3 subclasses makes for highly efficient activation of the complement system. ${ }^{65}$ The classical complement pathway is initiated by specific Abs binding at very high densities to the tightly packed nAChRs at the NMJ, resulting in C3 activation and cleavage of the downstream components of the complement cascade. The final step of the pathway consists of the formation and deposit of the membrane attack complex (MAC), with the subsequent destruction of postsynaptic folds. ${ }^{66}$ There have been several reports of complement-system activation at end plates, the strongest evidence being the identification of $\mathrm{Abs}, \mathrm{C}^{67}$ and $\mathrm{MAC}^{68}$ deposition at NMJ in MG patients, demonstrated by Engel's laboratory in the late 1970s. Correspondingly, serological consumption of complement components such as $\mathrm{C} 3$ and $\mathrm{C}^{69}$ and the presence of terminal components in plasma has also been proven in these patients. $^{70}$

IgG1 and IgG3 anti-nAChR antibodies can recognize different epitopes on the receptor macromolecule. The majority of the nAChR-Abs in MG patients bind to the MIR extracellular region of the $\alpha$-subunit. ${ }^{71}$ Anti-MIR Abs have been associated mostly with the generalized rather than with the ocular form of MG. Epitope mapping revealed that $\mathrm{nAChR}-\mathrm{Abs}$ can also bind to immunogenic parts of the $\beta$ and $\gamma$ subunits. ${ }^{72}$ Moreover, a study in an animal model proved that after immunization of animals with a short peptide from the $\alpha$ subunit, the immune response extended to the whole $\alpha$-chain, accounting for the spreading of the autoimmune response. ${ }^{73}$ This 'determinant spreading' occurs at the beginning of the autoimmune response, when the epitope targets scatter to adjacent subunits of the same molecule in MG patients. ${ }^{74}$

Recently, Noridomi and colleagues applied X-ray crystallography to solve the structure of the nAChR $\alpha 1$-subunit at $2.6 \AA$ resolution in complex with the Fab fragment of mAb35, an extensively studied monoclonal antibody that causes experimentally induced MG (EAMG) and competes with around $65 \%$ of human antibodies found in MG patients. ${ }^{12,22,75}$ The $\alpha 1$-subunit residues involved in the binding with the Fab are conserved across a wide range of species, a finding consistent with the cross-reactivity of autoantibodies in MG patients and EAMG animal models. ${ }^{71,72}$ Figure 2 illustrates in fine detail the
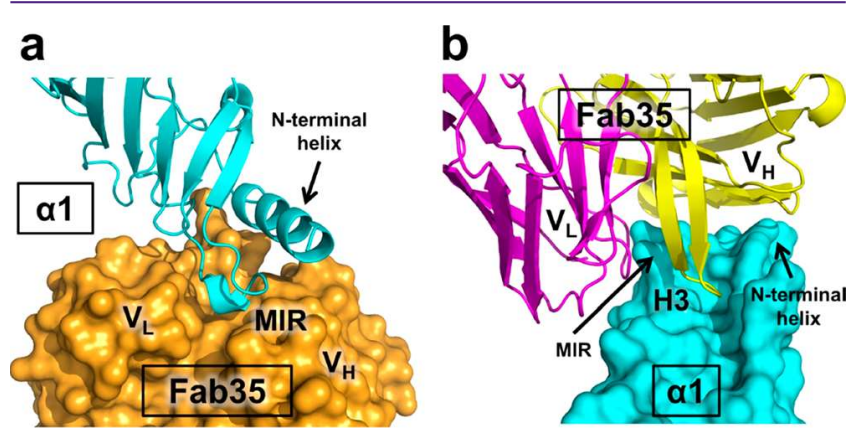

Figure 2. Key main immunogenic region (MIR) of the nAChR and its subtle but tight contact with the antibody. (a) The MIR loop of the nAChR $\alpha 1$-subunit inserts into a pocket of the Fab35 antibody fragment in the crystal structure. The pocket lies between the variable domains of the heavy $\left(\mathrm{V}_{\mathrm{H}}\right)$ and light $\left(\mathrm{V}_{\mathrm{L}}\right)$ chains of Fab35 (surfacerendered in orange color). The N-term helix of the nAChR $\alpha 1$ subunit sits on a groove of the $\mathrm{V}_{\mathrm{H}}$. In (b), the CDR-H3 (yellow $\beta$ strand labeled $\mathrm{H} 3$ ) of the $\mathrm{Fab} 35 \mathrm{~V}_{\mathrm{H}}$ region inserts into a pocket between the MIR loop and the N-term helix of the nAChR $\alpha 1$-subunit extracellular domain. From Noridomi et al. ${ }^{75}$

close contacts between the nAChR MIR and the Fab fragment of mAb35. ${ }^{75,76}$ The crystallographic studies not only disclose the intimate contact between the antigen-antibody contact domains, identifying the specific amino acid residues involved, but also give rise to new hypotheses concerning the phylogenetic conservation of the $\mathrm{Ab}$ recognition site in vertebrates. The $\mathrm{X}$-ray structures also provide insights into the functional domains involved, opening possibilities for diagnostic and therapeutic (drug design) developments in MG.

\section{MG INDUCED BY PROTEINS OTHER THAN THE nAChR}

A small proportion of MG patients are negative for nAChR-Ab. In 2001, Hoch and colleagues discovered that antibodies to MuSK were responsible for producing MG in about $70 \%$ of these myasthenic patients lacking nAChR-Ab ${ }^{41}$ (Table 1). MuSK is involved in the physiological maturation of $n A C h R$ aggregates at the NMJ. ${ }^{7 f}$ Although the MIR for MuSK is located on the most protruding portion of the first Ig-like domain of its extracellular moiety, Abs against multiple other epitopes have also been reported. ${ }^{17,78}$ Importantly, MuSK-Abs are predominantly of the IgG4 subtype, ${ }^{42}$ which are not capable of inducing complement activation. Furthermore, they 
are also bispecific Abs, i.e. they have the potential to exchange one of their Fab arms with any IgG4 molecule, ${ }^{79}$ so they are considered as functionally monovalent. Therefore, IgG4 Abs can only block function of MuSK signaling and lead to declustering of nAChRs, thereby destabilizing the NMJ. IgG4 Abs have no direct effect on MuSK dimerization or MuSK internalization; they bind to extracellular epitopes of MuSK, thus preventing the binding between MuSK and Lrp4, and consequently inhibit Agrin-stimulated MuSK phosphorylation. This leads to failure in the activation of the MuSK kinase domain, essential for the signaling which ends in nAChR clustering and maintenance of the NMJ. ${ }^{80,81}$ The distinct types of immunoglobulins involved may be partly responsible for the differences observed in the clinical evolution of patients affected by MuSK-Ab MG. ${ }^{43,44,82}$

Although other minor subtypes of Abs have been identified in patients with MG, which recognize mostly cytoplasmic muscle proteins (e.g., titin, myosin, actin and ryanodine receptor $)^{83}$ and other postsynaptic membrane or intracellular proteins (cortactin, LRP4, rapsyn), ${ }^{82,84-86}$ only anti-nAChR and anti-MuSK Abs have a well-characterized pathogenic role. However, anti-titin Abs have been strongly associated with the development of thymomas. ${ }^{83}$

Patients without nAChR-Abs or MuSK-Abs represent less than $10 \%$ of the total and are referred to as "seronegative MG" (SNMG). These patients have a clinical symptomatology and evolution similar to that of nAChR-Ab MG patients, and also a similar thymic pathology and responses to immunosuppressive treatment. ${ }^{42,44}$ SNMG patients are considered to have lowtiter, low-affinity nAChR-Ab that cannot be detected by the usual diagnostic techniques, mainly using radiolabeled soluble nAChR.

\section{- CLUSTERED SYNAPTIC RECEPTORS}

The NMJ is undoubtedly a large synapse, enormous in comparison to cholinergic or any other synapse in the CNS. $\mathrm{nAChR}$ clustering at the end-plate is a tightly regulated developmental phenomenon culminating in the formation of a relatively stable synapse, with more than 10 million receptor molecules tightly packed in an anatomically well-defined area of the muscle cell surface. Outside the synaptic area proper, the density of receptors drops dramatically. ${ }^{14}$ The mechanisms that regulate the density of $\mathrm{nAChRs}$ and other molecules at the vertebrate NMJ are now relatively well characterized, although there are still several aspects of this complex synapse that remain to be elucidated. One of the main outcomes of various decades of research into this area is the extensive knowledge on the interplay of multiple cascades and individual molecules involved in the anchoring, stabilization and maintenance of the end-plate synapse.

Before innervation, Wnt proteins together with the musclespecific kinase (MuSK) are involved in the formation of micron-sized aggregates of nAChRs ("microclusters"), in a process known as pre-patterning. ${ }^{87}$ This occurs at the central belt of the muscle cell, where the axonal nerve endings make their attempt to establish contact with the target cell. The small GTPase Rac1 is also involved at these early stages. At the innervated stage, another signaling pathway takes the leading role: agrin together with MuSK immunoglobulin-like domains 1 and 2 converge to produce the fusion of the microclusters into larger size aggregates, with the participation of another small GTPase: Rho1. The scaffolding cytoplasmic protein rapsyn also plays a key role in both pre- and postinnervation stages, cross-linking nAChRs. ${ }^{75}$ A reciprocal relationship exists between agrin and $\mathrm{ACh}$ in controlling $\mathrm{nAChRs}$ clustering: whereas agrin promotes clustering, $\mathrm{ACh}$ disperses the clusters. These opposing signals may allow stabilization of nAChRs at the NMJ, leading to dispersal of extrasynaptic nAChR-rich sites and formation of receptor clusters at the postjunctional membrane. ${ }^{88}$

There is evidence confirming the involvement of the Wnt $/ \beta$ catenin signaling pathway in neurodevelopment as well as in neurodegenerative diseases. Wnt $/ \beta$-catenin signaling occurs during critical periods in early development of the brain. Defects in this cascade have been hypothesized to occur in disorders such as autism ${ }^{89,90}$ and schizophrenia. ${ }^{91,92}$ Later in life, signaling pathways are essential for maintaining proper communication between neuronal and non-neuronal cells, and factors that disrupt this balance may result in disorders like Alzheimer disease. ${ }^{93}$ Other developmental disorders have also been linked to Rac-1 ${ }^{94}$ and also Rho1. ${ }^{95}$

Research in this area has disclosed a plethora of other postsynaptic proteins whose direct role in receptor supramolecular organization in the postsynaptic muscle cell is in many cases well established; in other cases, the involvement is of a subsidiary nature, either acting as coreceptors or stabilizing the receptor assemblies. Heat-shock proteins, which comprise tumorous imaginal disc 1 Short (Tid1S), play subsidiary roles in stabilizing nAChRs. MuSK activity is exerted at its transmembrane tyrosine kinase domain, acting directly in the formation of the NMJ. ${ }^{96,97}$ The so-called low-density lipoprotein receptor-related protein-4 (Lrp4) plays the role of receptor for signals that activate both the agrin and Wnt cascades providing "anterograde" signals for the clustering phenomenon. ${ }^{98,99}$ Retrograde signals mediated by the cysteinerich domain (CRD) and disheveled protein signaling cascade operate from the muscle cell to the nerve cell, with the participation of $\beta$-catenin. ${ }^{100,101}$ The laminin network is also recruited into the retrograde stabilization of the extracellular postsynaptic moiety of the end-plate, together with collagen $\mathrm{Q}$ and various connective tissue glycans. ${ }^{102}$ The muscle cell proper also provides glycans such as heparan sulfate and glycosaminoglycans, which might contribute to nAChR clustering by acting as muscle glycan agrin coreceptors. ${ }^{103,104}$ Muscle dystroglycans traverse the membrane and link the extracellular network, aiding in actin polymerization through Arp2/3, an actin-related complex. ${ }^{105}$

In 2008, Vincent and co-workers discovered Abs against clustered nAChR in up to $66 \%$ of SNMG patients, using a cellbased assay. ${ }^{106}$ This employs HEK cells cotransfected with human $\mathrm{nAChR}$ subunits and rapsyn to induce $\mathrm{nAChR}$ aggregation at the cell surface. ${ }^{107,108}$ Under these conditions, the in vitro assay can detect Abs of either low affinity or low concentration that the classical radioimmunological technique cannot. This is due to the fact that although, to the best of our knowledge, anticlustered $\mathrm{nAChR}$ Abs are the same as those identified using solubilized receptor as the antigen source, anticlustered $\mathrm{nAChR}$ Abs are able to bind much more strongly to the $\mathrm{nAChR}$ when the latter is presented in clustered form at the cell surface rather than free in solution as in the radioactive assay. This is possibly because they can conveniently cross-link the nAChRs through divalent binding, which is not likely to occur in solution. Abs against clustered $\mathrm{nAChR}$ belong to the IgG1-3 subclass, and are therefore able to activate the complement system and produce NMJ damage. ${ }^{106}$ Anticlustered $\mathrm{nAChRs}$ have been reported to occur in both ocular and 
generalized forms of the disease and their pathogenic nature was demonstrated by transferring patient IgG antibodies to mice. ${ }^{109}$ Patients with these "clustered-nAChR" antibodies generally resemble those with generalized MG (see Table 1) with typical RIA positive AChR antibodies, but their disease tends to be less severe. ${ }^{108,110}$

\section{Abs TO CLUSTERED RECEPTORS IN THE CNS}

Over the last 10 or so years, awareness of antibody-mediated diseases has expanded considerably. Autoantibodies directed specifically at neurotransmitter receptors are not exclusively found in the peripheral cholinergic synapse. They have also been reported to occur in the CNS. Several types of excitatory ion channel forming receptors ( $N$-methyl-D-aspartate receptor (NMDA-R), AMPAR, GABA $A$ R), one metabotropic receptor $\left(\mathrm{GABA}_{\mathrm{B}} \mathrm{R}\right)$, one inhibitory receptor (GlyR) and several proteins (LGI1, CASPR2, DPPX) that regulate the expression and localization of different forms of potassium channel have been identified in rare forms of brain encephalitis. The GlyR and the NMDA-R display selective clustering at the postsynaptic neuronal membrane. ${ }^{111,112}$ Abs that bind to the GlyR are associated with PERM (progressive encephalomyelitis with rigidity and myoclonus) and stiff-person syndrome ${ }^{113}$ and Abs against the NMDAR are found mainly in younger women with a complex form of encephalitis. ${ }^{114}$ Although both antibodies can bind divalently to their targets on the cell surface, and cause internalization and degradation of the receptors, anti-GlyR-Abs can also activate the complement system. ${ }^{12,115}$ Finally, another channel protein, the water channel aquaporin-4 (AQP4), which is a glial surface membrane protein expressed at the end feet of astrocytes in the CNS, also displays clustered forms, ${ }^{116}$ is the target for antibodies that act via complement-mediated and also complement-independent pathways in neuromyelitis optica spectrum disorders. ${ }^{117}$

\section{CONCLUSIONS}

The main factor determining the strength of the synapse is the number of receptors, which depends on the homeostatic equilibrium between two phenomena: (i) lateral diffusion ${ }^{118}$ into and out of the synaptic region from/to nonsynaptic (extrasynaptic) areas, and (ii) the trafficking and turnover of receptors, determined by the rate and extent of biosynthetic and exocytic delivery to the plasmalemma on the one hand, and removal from the cell surface by internalization (endocytosis) on the other. ${ }^{119}$ This is a highly dynamic scenario in which receptor supramolecular association and dissociation contribute to the efficacy of synaptic transmission, in both central and peripheral synapses. The main pathophysiological finding of deficient neurotransmission in the peripheral autoimmune synaptopathies, MG and related diseases, is an epiphenomenon of the loss of synaptic receptors. Such loss has become more widely appreciated in several neurological conditions and brain pathologies. The detailed knowledge acquired on the physiopathology of the peripheral cholinergic synapse provides a solid basis on which to build testable hypotheses to understand some of these CNS diseases.

\section{AUTHOR INFORMATION}

\section{Corresponding Author}

*E-mail: rtfjb1@gmail.com.
ORCID

Francisco J. Barrantes: 0000-0002-4745-681X

\section{Author Contributions}

F.J.B. conceived the idea, and M.L.P. and F.J.B. wrote the review.

\section{Funding}

This work was supported by Grants PIP No. 112-20110101023 and 5205/15 from the National Scientific and Technical Research Council of Argentina (CONICET) and PICT No. 2015-2654 from Mincyt, Argentina, to F.J.B.

\section{Notes}

The authors declare no competing financial interest.

\section{ACKNOWLEDGMENTS}

Authors are grateful to Prof. Angela Vincent for critically reading and providing helpful suggestions during revision of this manuscript.

\section{ABBREVIATIONS USED}

Ab, antibody; BTX, $\alpha$-bungarotoxin; mAb, monoclonal antibody; $\mathrm{nAChR}$, nicotinic acetylcholine receptor; $\mathrm{MG}$, myasthenia gravis; MuSK, muscle-specific kinase.

\section{REFERENCES}

(1) Barrantes, F. J. (2015) Phylogenetic Conservation of Proteinlipid Motifs in Pentameric Ligand-Gated Ion Channels. Biochim. Biophys. Acta, Biomembr. 1848 (9), 1796-1805.

(2) Le Novère, N., and Changeux, J. P. (1999) The Ligand Gated Ion Channel Database. Nucleic Acids Res. 27 (1), 340-342.

(3) Ashcroft, F. Ion Channels and Disease; Academic Press, 1999.

(4) Dineley, K. T., Pandya, A. A., and Yakel, J. (2015) Nicotinic ACh Receptors as Therapeutic Targets in CNS Disorders. Trends Pharmacol. Sci. 36 (2), 96-108.

(5) Deutsch, S. I., Burket, J. A., Benson, A. D., and Urbano, M. R. (2016) The 15q13.3 Deletion Syndrome: Deficient A7-Containing Nicotinic Acetylcholine Receptor-Mediated Neurotransmission in the Pathogenesis of Neurodevelopmental Disorders. Prog. NeuroPsychopharmacol. Biol. Psychiatry 64, 109-117.

(6) Posadas, I., Lopez-Hernandez, B., and Cena, V. (2013) Nicotinic Receptors in Neurodegeneration. Curr. Neuropharmacol. 11 (3), 298314.

(7) Zoli, M., Pucci, S., Vilella, A., and Gotti, C. (2018) Neuronal and Extraneuronal Nicotinic Acetylcholine Receptors. Curr. Neuropharmacol. 16 (4), 338-349.

(8) Friedman, J. R., Richbart, S. D., Merritt, J. C., Brown, K. C., Nolan, N. A., Akers, A. T., Lau, J. K., Robateau, Z. R., Miles, S. L., and Dasgupta, P. (2018) Acetylcholine Signaling System in Progression of Lung Cancers. Pharmacol. Ther. 194, 222-251.

(9) Wang, S., and Hu, Y. (2018) A7 Nicotinic Acetylcholine Receptors in Lung Cancer. Oncol. Lett. 16 (2), 1375-1382.

(10) Zhao, Y. (2016) The Oncogenic Functions of Nicotinic Acetylcholine Receptors. J. Oncol. 2016, 1.

(11) Mucchietto, M., Crespi, A., Fasoli, F., Clementi, F., and Gotti, C. (2016) Neuronal Acetylcholine Nicotinic Receptors as New Targets for Lung Cancer Treatment. Curr. Pharm. Des. 22 (14), $2160-2169$.

(12) Lindstrom, J. (2000) Acetylcholine Receptors and Mysthenia. Muscle Nerve 23 (April), 453-477.

(13) Leite, M. I., Waters, P., and Vincent, A. (2010) Diagnostic Use of Autoantibodies in Myasthenia Gravis. Autoimmunity 43 (5-6), 371.

(14) Barrantes, F. J. (1988) Muscle Endplate Cholinoreceptors. Pharmacol. Ther. 38 (3), 331-385.

(15) Vincent, A. (2002) Unravelling the Pathogenesis of Myasthenia Gravis. Nat. Rev. Immunol. 2 (10), 797-804. 
(16) Meriggioli, M., and Sanders, D. (2009) Autoimmune Myasthenia Gravis: Emerging Clinical and Biological Heterogeneity. Lancet Neurol. 8 (5), 475-490.

(17) Huijbers, M. G., Lipka, A. F., Plomp, J. J., Niks, E. H., van der Maarel, S. M., and Verschuuren, J. J. (2014) Pathogenic Immune Mechanisms at the Neuromuscular Synapse: The Role of Specific Antibody-Binding Epitopes in Myasthenia Gravis. J. Intern. Med. 275 (1), 12-26.

(18) Berrih-Aknin, S. (2014) Myasthenia Gravis: Paradox versus Paradigm in Autoimmunity. J. Autoimmun. 52, 1-28.

(19) Vincent, A., Huda, S., Cao, M., Cetin, H., Koneczny, I., Rodriguez Cruz, P. M., Jacobson, L., Viegas, S., Jacob, S., Woodhall, M., et al. (2018) Serological and Experimental Studies in Different Forms of Myasthenia Gravis. Ann. N. Y. Acad. Sci. 1413 (1), 143-153.

(20) Mathews, G. (2001) Cellular Physiology of Nerve and Muscle, Blackwell Publishing Co.

(21) Barrantes, F. J. (1983) Recent Developments in the Structure and Function of the Acetylcholine Receptor. Int. Rev. Neurobiol. 24, 259-341.

(22) Lindstrom, J., Luo, J., and Kuryatov, A. (2008) Myasthenia Gravis and the Tops and Bottoms of AChRs: Antigenic Structure of the MIR and Specific Immunosuppression of EAMG Using AChR Cytoplasmic Domains. Ann. N. Y. Acad. Sci. 1132, 29-41.

(23) Changeux, J. P., Kasai, M., and Lee, C. Y. (1970) Use of a Snake Venom Toxin to Characterize the Cholinergic Receptor Protein. Proc. Natl. Acad. Sci. U. S. A. 67 (3), 1241-1247.

(24) Cecchini, M., and Changeux, J. P. (2015) The Nicotinic Acetylcholine Receptor and Its Prokaryotic Homologues: Structure, Conformational Transitions \& Allosteric Modulation. Neuropharmacology 96 (PB), 137-149.

(25) Zuber, B., and Unwin, N. (2013) Structure and Superorganization of Acetylcholine Receptor-Rapsyn Complexes. Proc. Natl. Acad. Sci. U. S. A. 110 (26), 10622-10627.

(26) Neher, E., and Sakmann, B. (1976) Noise Analysis of Drug Induced Voltage Clamp Currents in Denervated Frog Muscle Fibres. J. Physiol. 258, 705-729.

(27) Hamill, O., and Sakmann, B. (1981) Multiple Conductance States of Single Acetylcholine Receptor Channels in Embryonic Muscle Cells. Nature 294 (5840), 462-464.

(28) Hamill, O. P., Marty, A., Neher, E., Sakmann, B., and Sigworth, F. J. (1981) Improved Patch-Clamp Techniques for High-Resolution Current Recording from Cells and Cell-Free Membrane Patches. Pfluegers Arch. 391 (2), 85-100.

(29) Luo, J., and Lindstrom, J. (2010) Antigenic Structure of the Human Muscle Nicotinic Acetylcholine Receptor Main Immunogenic Region. J. Mol. Neurosci. 40 (1-2), 217-220.

(30) Rose, N. R., and Bona, C. (1993) Defining Criteria for Autoimmune Diseases (Witebsky's Postulates Revisited). Immunol. Today 14 (9), 426-430.

(31) Lindstrom, J. M., Seybold, M. E., Lennon, V. a., Whittingham, S., and Duane, D. D. (1976) Antibody to Acetylcholine Receptor in Myasthenia Gravis: Prevalence, Clinical Correlates, and Diagnostic Value. Neurology 26 (11), 1054-1054.

(32) Carr, A. S., Cardwell, C. R., McCarron, P. O., and McConville, J. (2010) A Systematic Review of Population Based Epidemiological Studies in Myasthenia Gravis. BMC Neurol. 10, 46.

(33) Heldal, A. T., Owe, J. F., Gilhus, N. E., and Romi, F. (2009) Seropositive Myasthenia Gravis: A Nationwide Epidemiologic Study. Neurology 73, 150-151.

(34) Berrih-Aknin, S., Frenkian-Cuvelier, M., and Eymard, B. (2014) Diagnostic and Clinical Classification of Autoimmune Myasthenia Gravis. J. Autoimmun. 48-49, 143-148.

(35) Gajdos, P., Tranchant, C., Clair, B., Bolgert, F., Eymard, B., Stojkovic, T., Attarian, S., and Chevret, S. (2005) Treatment of Myasthenia Gravis Exacerbation with Intravenous Immunoglobulin: A Randomized Double-Blind Clinical Trial. Arch. Neurol. 62, 16891693.
(36) Kuks, J. B. (2009) Clinical Presentation and Epidemiology of Myasthenia Gravis. In Myasthenia Gravis and Related Disorders (Current Clinical Neurology), Humana Press.

(37) Gilhus, N. E., and Verschuuren, J. J. (2015) Myasthenia Gravis: Subgroup Classification and Therapeutic Strategies. Lancet Neurol. 14, 1023-1036.

(38) Vincent, A., and Newsom-Davis, J. (1985) Acetylcholine Receptor Antibody as a Diagnostic Test for Myasthenia Gravis: Results in 153 Validated Cases and 2967 Diagnostic Assays. J. Neurol., Neurosurg. Psychiatry 48 (12), 1246-1252.

(39) Berrih, S., Morel, E., Gaud, C., Raimond, F., Le Brigand, H., and Bach, J. F. (1984) Anti-AChR Antibodies, Thymic Histology, and T Cell Subsets in Myasthenia Gravis. Neurology 34 (1), 66-71.

(40) Leite, M. I., Jones, M., Ströbel, P., Marx, A., Gold, R., Niks, E., Verschuuren, J. G. M., Berrih-Aknin, S., Scaravilli, F., Canelhas, A., et al. (2007) Myasthenia Gravis Thymus. Am. J. Pathol. 171 (3), 893905.

(41) Hoch, W., McConville, J., Helms, S., Newsom-Davis, J., Melms, A., and Vincent, a. (2001) Auto-Antibodies to the Receptor Tyrosine Kinase MuSK in Patients with Myasthenia Gravis without Acetylcholine Receptor Antibodies. Nat. Med. 7 (3), 365-368.

(42) McConville, J., Farrugia, M. E., Beeson, D., Kishore, U., Metcalfe, R., Newsom-Davis, J., and Vincent, A. (2004) Detection and Characterization of MuSK Antibodies in Seronegative Myasthenia Gravis. Ann. Neurol. 55 (4), 580-584.

(43) Farrugia, M. E., Robson, M. D., Clover, L., Anslow, P., Newsom-Davis, J., Kennett, R., Hilton-Jones, D., Matthews, P. M., and Vincent, A. (2006) MRI and Clinical Studies of Facial and Bulbar Muscle Involvement in MuSK Antibody-Associated Myasthenia Gravis. Brain 129 (6), 1481-1492.

(44) Leite, M. I., Ströbel, P., Jones, M., Micklem, K., Moritz, R., Gold, R., Niks, E. H., Berrih-Aknin, S., Scaravilli, F., Canelhas, A., et al. (2005) Fewer Thymic Changes in MuSK Antibody-Positive than in MuSK Antibody-Negative MG. Ann. Neurol. 57 (3), 444-448.

(45) Batocchi, A. P., Evoli, A., Palmisani, M. T., Lo Monaco, M., Bartoccioni, M., and Tonali, P. (1990) Early-Onset Myasthenia Gravis: Clinical Characteristics and Response to Therapy. Eur. J. Pediatr. 150 (1), 66-68.

(46) Weis, C. A., Schalke, B., Ströbel, P., and Marx, A. (2018) Challenging the Current Model of Early-Onset Myasthenia Gravis Pathogenesis in the Light of the MGTX Trial and Histological Heterogeneity of Thymectomy Specimens. Ann. N. Y. Acad. Sci. 1413 (1), 82-91.

(47) Cron, M. A., Maillard, S., Villegas, J., Truffault, F., Sudres, M., Dragin, N., Berrih-Aknin, S., and Le Panse, R. (2018) Thymus Involvement in Early-Onset Myasthenia Gravis. Ann. N. Y. Acad. Sci. 1412 (1), 137-145.

(48) Compston, D. A. S., Vincent, A., Newsom-davis, J., and Batchelor, J. R. (1980) Clinical, Pathological, Hla Antigen and Immunological Evidence for Disease Heterogeneity in Myasthenia Gravis. Brain 103 (3), 579-601.

(49) Živković, S. A., Clemens, P. R., and Lacomis, D. (2012) Characteristics of Late-Onset Myasthenia Gravis. J. Neurol. 259 (10), 2167-2171.

(50) Szczudlik, P., Szyluk, B., Lipowska, M., Ryniewicz, B., Kubiszewska, J., Dutkiewicz, M., Gilhus, N. E., and KosteraPruszczyk, A. (2014) Antititin Antibody in Early- and Late-Onset Myasthenia Gravis. Acta Neurol. Scand. 130 (4), 229-233.

(51) Aarli, J. A. (1999) Late-Onset Myasthenia Gravis. Arch. Neurol. 56 (1), 25-27.

(52) Santos, E., Bettencourt, A., da Silva, A. M., Boleixa, D., Lopes, D., Brás, S., Costa, P. P. e., Lopes, C., Gonçalves, G., Leite, M. I., et al. (2017) HLA and Age of Onset in Myasthenia Gravis. Neuromuscul. Disord. 27 (7), 650-654.

(53) Vincent, A., Clover, L., Buckley, C., Evans, G., and Rothwell, P. M. (2003) Evidence of Underdiagnosis of Myasthenia Gravis in Older People. J. Neurol., Neurosurg. Psychiatry 74, 1105-1108.

(54) Nishikawa, N., Nagai, M., Tsujii, T., Kyaw, W. T., Tanabe, N., Iwaki, H., Yabe, H., Ando, R., and Nomoto, M. (2015) Treatment of 
Myasthenia Gravis in Patients with Elderly Onset at Advanced Age. Jpn. Clin. Med. 6, 9-13.

(55) Owe, J. F., Daltveit, A. K., and Gilhus, N. E. (2006) Causes of Death among Patients with Myasthenia Gravis in Norway between 1951 and 2001. J. Neurol., Neurosurg. Psychiatry 77 (2), 203-207.

(56) Suhail, H., Soundararajan, C. C., Vivekanandhan, S., Singh, S., and Behari, M. (2010) Apolipoprotein-E Genotypes and Myasthenia Gravis. Neurol. India 58 (3), 443-446.

(57) Šštarko, M., Sertic, J., Greguric, N., Stavljenic-Rukavina, A., Brzovic, Z., and Matic, V. (1998) Apolipoprotein E in Myasthenia Gravis. Ann. N. Y. Acad. Sci. 841, 592-595.

(58) Palace, J., and Beeson, D. (2008) The Congenital Myasthenic Syndromes. J. Neuroimmunol. 201-202 (C), 2-5.

(59) Beeson, D., Webster, R., Cossins, J., Lashley, D., Spearman, H., Maxwell, S., Slater, C. R., Newsom-Davis, J., Palace, J., and Vincent, A. (2008) Congenital Myasthenic Syndromes and the Formation of the Neuromuscular Junction. Ann. N. Y. Acad. Sci. 1132 (1), 99-103.

(60) Cruz, P. M. R., Palace, J., and Beeson, D. (2014) Congenital Myasthenic Syndromes and the Neuromuscular Junction. Curr. Opin. Neurol. 27 (5), 566-575.

(61) Rodríguez-Cruz, P. M., Palace, J., and Beeson, D. (2018) The Neuromuscular Junction and Wide Heterogeneity of Congenital Myasthenic Syndromes. Int. J. Mol. Sci. 19 (6), 1677.

(62) Ruff, R. L., and Lisak, R. P. (2018) Nature and Action of Antibodies in Myasthenia Gravis. Neurol. Clin. 36 (2), 275-291.

(63) Gomez, A. M., Van Den Broeck, J., Vrolix, K., Janssen, S. P., Lemmens, M. A. M., Van Der Esch, E., Duimel, H., Frederik, P., Molenaar, P. C., Martínez-Martínez, P., et al. (2010) Antibody Effector Mechanisms in Myasthenia Gravis-Pathogenesis at the Neuromuscular Junction. Autoimmunity 43 (5-6), 353-370.

(64) Drachman, D. B., Adams, R. N., Stanley, E. F., and Pestronk, A. (1980) Mechanisms of Acetylcholine Receptor Loss in Myasthenia Gravis. J. Neurol., Neurosurg. Psychiatry 43 (7), 601-610.

(65) Rødgaard, A., Nielsen, F. C., Djurup, R., Somnier, F., and Gammeltoft, S. (1987) Acetylcholine Receptor Antibody in Myasthenia Gravis: Predominance of IgG Subclasses 1 and 3. Clin. Exp. Immunol. 67 (1), 82-88.

(66) Kusner, L. L., Kaminski, H. J., and Soltys, J. (2008) Effect of Complement and Its Regulation on Myasthenia Gravis Pathogenesis. Expert Rev. Clin. Immunol. 4 (1), 43-52.

(67) Engel, A. G., Lambert, E. H., and Howard, F. M. (1977) Immune Complexes (IgG and C3) at the Motor End-Plate in Myasthenia Gravis: Ultrastructural and Light Microscopic Localization and Electrophysiologic Correlations. Mayo Clin. Proc. 52 (5), 267-280.

(68) Sahashi, K., Engel, A. G., Lambert, E. H., and Howard, F. M. (1980) Ultrastructural Localization of the Terminal and Lytic Ninth Complement Component (C9) at the Motor End-Plate in Myasthenia Gravis. J. Neuropathol. Exp. Neurol. 39 (2), 160-172.

(69) Romi, F., Kristoffersen, E. K., Aarli, J. a, and Gilhus, N. E. (2005) The Role of Complement in Myasthenia Gravis: Serological Evidence of Complement Consumption in Vivo. J. Neuroimmunol. 158 (1-2), 191-194.

(70) Barohn, R. J., and Brey, R. L. (1993) Soluble Terminal Complement Components in Human Myasthenia Gravis. Clin. Neurol. Neurosurg. 95 (1), 285-290.

(71) Tzartos, S. J., Seybold, M. E., and Lindstrom, J. M. (1982) Specificities of Antibodies to Acetylcholine Receptors in Sera from Myasthenia Gravis Patients Measured by Monoclonal Antibodies. Proc. Natl. Acad. Sci. U. S. A. 79 (1), 188-192.

(72) Tzartos, S. J., Morel, E., Efthimiadis, A., Bustarret, A. F., D'Anglejan, J., Drosos, A. A., and Moutsopoulos, H. A. (1988) Fine Antigenic Specificities of Antibodies in Sera from Patients with DPenicillamine-Induced Myasthenia Gravis. Clin. Exp. Immunol. 74, $80-86$.

(73) Vincent, A., Jacobson, L., and Shillito, P. (1994) Response to Human Acetylcholine Receptor A138-199: Determinant Spreading Initiates Autoimmunity to Self-Antigen in Rabbits. Immunol. Lett. 39 (3), 269-275.
(74) Vanderlugt, C., and Miller, S. (1996) Epitope Spreading. Curr. Opin. Immunol. 8 (6), 831-836.

(75) Noridomi, K., Watanabe, G., Hansen, M. N., Han, G. W., and Chen, L. (2017) Structural Insights into the Molecular Mechanisms of Myasthenia Gravis and Their Therapeutic Implications. eLife 6, 120.

(76) Li, S., Huang, S., Bren, N., Noridomi, K., Dellisanti, C., Sine, S., and Chen, L. (2011) Ligand-Binding Domain of an A7 -Nicotinic Receptor Chimera and Its Complex with Agonist. Nat. Neurosci. 14 (10), 1253-1259.

(77) DeChiara, T. M., Bowen, D. C., Valenzuela, D. M., Simmons, M. V., Poueymirou, W. T., Thomas, S., Kinetz, E., Compton, D. L., Rojas, E., Park, J. S., et al. (1996) The Receptor Tyrosine Kinase MuSK Is Required for Neuromuscular Junction Formation In Vivo. Cell 85 (4), 501-512.

(78) Takamori, M., Nakamura, T., and Motomura, M. (2013) Antibodies against Wnt Receptor of Muscle-Specific Tyrosine Kinase in Myasthenia Gravis. J. Neuroimmunol. 254, 183-186.

(79) Koneczny, I., Stevens, J. A. A., De Rosa, A., Huda, S., Huijbers, M. G., Saxena, A., Maestri, M., Lazaridis, K., Zisimopoulou, P., Tzartos, S., et al. (2017) IgG4 Autoantibodies against Muscle-Specific Kinase Undergo Fab-Arm Exchange in Myasthenia Gravis Patients. J. Autoimmun. 77, 104-115.

(80) Huijbers, M. G., Zhang, W., Klooster, R., Niks, E. H., Friese, M. B., Straasheijm, K. R., Thijssen, P. E., Vrolijk, H., Plomp, J. J., Vogels, P., et al. (2013) MuSK IgG4 Autoantibodies Cause Myasthenia Gravis by Inhibiting Binding between MuSK and Lrp4. Proc. Natl. Acad. Sci. U. S. A. 110 (51), 20783-20788.

(81) Farrugia, M. E., Bonifati, D. M., Clover, L., Cossins, J., Beeson, D., and Vincent, A. (2007) Effect of Sera from AChR-Antibody Negative Myasthenia Gravis Patients on AChR and MuSK in Cell Cultures. J. Neuroimmunol. 185 (1-2), 136-144.

(82) Rivner, M. H., Pasnoor, M., Dimachkie, M. M., Barohn, R. J., and Mei, L. (2018) Muscle-Specific Tyrosine Kinase and Myasthenia Gravis Owing to Other Antibodies. Neurol. Clin. 36 (2), 293-310.

(83) Romi, F., Skeie, G. O., Gilhus, N. E., and Aarli, J. A. (2005) Striational Antibodies in Myasthenia Gravis. Arch. Neurol. 62 (3), 442.

(84) Gallardo, E., Martínez-Hernández, E., Titulaer, M. J., Huijbers, M. G., Martínez, M. A., Ramos, A., Querol, L., Díaz-Manera, J., RojasGarcía, R., and Hayworth, C. R. (2014) Cortactin Autoantibodies in Myasthenia Gravis. Autoimmun. Rev. 13, 1003.

(85) Higuchi, O., Hamuro, J., Motomura, M., and Yamanashi, Y. (2011) Autoantibodies to Low-Density Lipoprotein Receptor-Related Protein 4 in Myasthenia Gravis. Ann. Neurol. 69 (2), 418-422.

(86) Agius, M. A., Zhu, S., Kirvan, C. A., Schafer, A. L., Lin, M. Y., Fairclough, R. H., Oger, J. J. F., Aziz, T., and Aarli, J. A. (1998) Rapsyn Antibodies in Myasthenia Gravis. Ann. N. Y. Acad. Sci. 841, 516-521.

(87) Shen, C., Li, L., Zhao, K., Bai, L., Wang, A., Shu, X., Xiao, Y., Zhang, J., Zhang, K., Hui, T., et al. (2018) Motoneuron Wnts Regulate Neuromuscular Junction Development. eLife 7, 1-18.

(88) Chen, F., Qian, L., Yang, Z., Huang, Y., Ngo, S., Ruan, N., Wang, J., Schneider, C., Noakes, P., Ding, Y., et al. (2007) Rapsyn Interaction with Calpain Stabilizes AChR Clusters at the Neuromuscular Junction. Neuron 55 (2), 247-260.

(89) Wassink, T. H., Piven, J., Vieland, V. J., Huang, J., Swiderski, R. E., Pietila, J., Braun, T., Beck, G., Folstein, S. E., Haines, J. L., et al. (2001) Rapid Publication Evidence Supporting WNT2 as an Autism Susceptibility Gene. Am. J. Med. Genet. (Neuropsychiatric Genet. 105, 406-413.

(90) Benayed, R., Gharani, N., Rossman, I., Mancuso, V., Lazar, G., Kamdar, S., Bruse, S. E., Tischfield, S., Smith, B. J., Zimmerman, R. A., et al. (2005) Support for the Homeobox Transcription Factor Gene ENGRAILED 2 as an Autism Spectrum Disorder Susceptibility Locus. Am. J. Hum. Genet. 77, 851-868.

(91) Ftouh, S., Akbar, M. T., Hirsch, S. R., and De Belleroche, J. S. (2005) Down-Regulation of Dickkopf 3, a Regulator of the Wnt Signalling Pathway, in Elderly Schizophrenic Subjects. J. Neurochem. 94, 520-530. 
(92) Cotter, D., Kerwin, C. A. R., Al-sarraji, S., Brion, J. P., Chadwich, A., Lovestone, S., Anderton, B., and Everall, I. (1998) Abnormalities of Wnt Signalling in Schizophrenia - Evidence for Neurodevelopmental Abnormality. NeuroReport 9 (7), 1379-1383.

(93) Phiel, C. J., Wilson, C. A., Lee, V. M., and Klein, P. S. (2003) GSK-3 a Regulates Production of Alzheimer's Disease Amyloid- b Peptides. Nature 423, 435-439.

(94) Reijnders, M. R. F., Ansor, N. M., Kousi, M., Yue, W. W., Tan, P. L., Clarkson, K., Clayton-smith, J., Corning, K., Jones, J. R., Lam, W. W. K., et al. (2017) RAC1Missense Mutations in Developmental Disorders with Diverse Phenotypes. Am. J. Hum. Genet. 101 (3), 466477.

(95) Hariharan, I. K., Hu, K., Asha, H., Quintanilla, A., Ezzell, R. M., and Settleman, J. (1995) Characterization of Rho GTPase Family Homologues in Drosophila Melanogaster: Overexpressing Rhol in Retinal Cells Causes a Late Developmental Defect. EMBO J. 14 (2), 292-302.

(96) Inoue, A., Setoguchi, K., Matsubara, Y., Okada, K., Sato, N., Iwakura, Y., Higuchi, O., and Yamanashi, Y. (2009) Dok-7 Activates the Muscle Receptor Kinase MuSK and Shapes Synapse Formation. Sci. Signaling 2 (59), 1-9.

(97) Messeant, J., Dobbertin, A., Girard, E., Delers, P., Manuel, X., Mangione, F., Schmitt, A., Le Denmat, D., Molgo, J., Zytnicki, D., et al. (2015) MuSK Frizzled-Like Domain Is Critical for Mammalian Neuromuscular Junction Formation and Maintenance and X Laure Strochlic. J. Neurosci. 35 (12), 4926-4941.

(98) Zong, Y., and Jin, R. (2013) Structural Mechanisms of the Agrin-LRP4-MuSK Signaling Pathway in Neuromuscular Junction Differentiation. Cell. Mol. Life Sci. 70 (17), 3077-3088.

(99) Barik, A., Zhang, B., Sohal, G. S., Xiong, W., and Mei, L. (2014) Crosstalk Between Agrin and Wnt Signaling Pathways in Development of Vertebrate Neuromuscular Junction. Dev. Neurobiol. 74, 828838.

(100) Wang, J., Ruan, N., Qian, L., Lei, W., Chen, F., and Luo, Z. (2008) Wnt /B-Catenin Signaling Suppresses Rapsyn Expression and Inhibits Acetylcholine Receptor Clustering at the Neuromuscular Junction. J. Biol. Chem. 283 (31), 21668-21675.

(101) Ponferrada, V. G., Fan, J., Vallance, J. E., Mamedova, A., Hu, S., Rankin, S. A., Kofron, M., Zorn, A. M., Hegde, R. S., and Lang, R. A. (2012) CRIM1 Complexes with SS-Catenin and Cadherins, Stabilizes Cell-Cell Junctions and Is Critical for Neural Morphogenesis. PLoS One 7 (3), No. e32635.

(102) Smirnov, S. P., Barzaghi, P., Mckee, K. K., Ruegg, M. A., and Yurchenco, P. D. (2005) Conjugation of LG Domains of Agrins and Perlecan to Polymerizing Laminin-2 Promotes Acetylcholine Receptor Clustering. J. Biol. Chem. 280 (50), 41449-41457.

(103) Mook-Jung, I., and Gordon, H. (1995) Acetylcholine Receptor Clustering in C2Muscle Cells Requires Chondroitin Sulfate. J. Neurobiol. 28 (4), 482-492.

(104) Mcdonnell, K. M. W., and Grow, W. A. (2004) Reduced Glycosaminoglycan Sulfation Diminishes the Agrin Signal Transduction Pathway. Dev. Neurosci. 26, 1-10.

(105) Humphries, C. L., Balcer, H. I., D'Agostino, J. L., Winsor, B., Drubin, D. G., Barnes, G., Andrews, B. J., and Goode, B. L. (2002) Direct Regulation of Arp2/3 Complex Activity and Function by the Actin Binding Protein Coronin. J. Cell Biol. 159 (6), 993-1004.

(106) Leite, M. I., Jacob, S., Viegas, S., Cossins, J., Clover, L., Morgan, B. P., Beeson, D., Willcox, N., and Vincent, A. (2008) IgG1 Antibodies to Acetylcholine Receptors in "seronegative" Myasthenia Gravis. Brain 131 (7), 1940-1952.

(107) Rodriguez Cruz, P. M., Huda, S., López-Ruiz, P., and Vincent, A. (2015) Use of Cell-Based Assays in Myasthenia Gravis and Other Antibody-Mediated Diseases. Exp. Neurol. 270, 66-71.

(108) Rodríguez Cruz, P. M., Al-Hajjar, M., Huda, S., Jacobson, L., Woodhall, M., Jayawant, S., Buckley, C., Hilton-Jones, D., Beeson, D., Vincent, A., et al. (2015) Clinical Features and Diagnostic Usefulness of Antibodies to Clustered Acetylcholine Receptors in the Diagnosis of Seronegative Myasthenia Gravis. JAMA Neurol. 72 (6), 642-649.
(109) Jacob, S., Viegas, S., Leite, M. I., Webster, R., Cossins, J., Kennett, R., Hilton-Jones, D., Morgan, B. P., and Vincent, A. (2012) Presence and Pathogenic Relevance of Antibodies to Clustered Acetylcholine Receptor in Ocular and Generalized Myasthenia Gravis. Arch. Neurol. 69 (8), 994-10005.

(110) Devic, P., Petiot, P., Simonet, T., Stojkovic, T., Delmont, E., Franques, J., Magot, A., Vial, C., Lagrange, E., Nicot, A. S., et al. (2014) Antibodies to Clustered Acetylcholine Receptor: Expanding the Phenotype. Eur. J. Neurol. 21 (1), 130-134.

(111) Meier, J., Meunier-Durmort, J., Forest, C., T, A., and V, C. (2000) Formation of Glycine Receptor Clusters and Their Accumulation at Synapses. J. Cell Sci. 113, 2783-2795.

(112) Michaelis, E. K. (1998) Molecular Biology of Glutamate Receptors in the Central Nervous System and Their Role in Excitotoxicity, Oxidative Stress and Aging. Prog. Neurobiol. 54, $369-415$.

(113) Hinson, S. R., Lopez-Chiriboga, A. S., Bower, J. H., Matsumoto, J. Y., Hassan, A., Basal, E., Lennon, V. A., Pittock, S. J., and McKeon, A. (2018) Glycine Receptor Modulating Antibody Predicting Treatable Stiff-Person Spectrum Disorders. Neurol. Neuroimmunol. NeuroInflammation 5 (2), e438.

(114) Dalmau, J., Gleichman, A. J., Hughes, E. G., Rossi, J. E., Peng, X., Lai, M., Dessain, S. K., Rosenfeld, M. R., Balice-Gordon, R., Lynch, D. R., et al. (2008) Anti-NMDA-Receptor Encephalitis: Case Series and Analysis of the Effects of Antibodies. Lancet Neurol. 7 (12), 1091-1098.

(115) Carvajal-GonzáLez, A., Leite, M., Waters, P., Woodhall, M., Coutinho, E., Balint, B., Lang, B., Pettingill, P., Carr, A., Sheerin, U.M., et al. (2014) Glycine Receptor Antibodies in PERM and Related Syndromes: Characteristics, Clinical Features and Outcomes. Brain 137, 2178-2192.

(116) Smith, A. J., and Verkman, A. S. (2015) Superresolution Imaging of Aquaporin-4 Cluster Size in Antibody-Stained Paraffin Brain Sections. Biophys. J. 109, 2511-2522.

(117) Ikeshima-Kataoka, H. (2016) Neuroimmunological Implications of AQP4 in Astrocytes. Int. J. Mol. Sci. 17, 1306-1322.

(118) Almarza, G., Sánchez, F., and Barrantes, F. J. (2014) Transient Cholesterol Effects on Nicotinic Acetylcholine Receptor Cell-Surface Mobility. PLoS One 9 (6), e100346.

(119) Fumagalli, G., Engel, A. G., and Lindstrom, J. (1982) Ultrastructural aspect of acetylcholine receptor turnover at the normal end-plate and in autoimmune myasthenia gravis. J. Neuropathol. Exp. Neurol. 41, 567-579. 